\title{
Ars iusphilosophica. Entrevista a Manuel Atienza(*)(**)
}

\section{Ars iusphilosophica. An interview with Manuel Atienza}

\begin{abstract}
Resumen: Esta es una entrevista realizada al jurista, filósofo y escritor español Manuel Atienza Rodríguez, la cual tiene por principal objetivo realizar un seguimiento de los sucesos más relevantes que influyeron dentro de su proceso de formación académica. Este encuentro no solamente nos permite descubrir la dinámica relacional que guardaban Atienza y sus referentes, sino que también nos ofrece su visión acerca de asuntos puestos a debatir dentro de la materia iusfilosófica. A lo largo de la entrevista, Atienza se dispone a cortar con los paradigmas tradicionales del iuspositivismo, para poder dar paso a nuevas teorías que permitan orientar las prácticas jurídicas modernas. Asimismo, si bien respalda la significación de la argumentación dentro del Derecho, remarca la importancia de la aplicación de un objetivismo moral mínimo durante el desarrollo argumentativo. Finalmente, nos comenta acerca de la evolución que las escuelas latinoamericanas han venido logrando y la trascendencia que, presiente, tendrán en un futuro.
\end{abstract}

Palabras clave: Filosofía del Derecho - lusfilosofía - lusnaturalismo - Positivismo jurídico - Pospositivismo - Neoconstitucionalismo

\begin{abstract}
In this interview, the Spanish lawyer, philosopher and writer Manuel Atienza Rodriguez tells us about the most relevant events that have influenced his academic formation. This meeting allows us to discover the dynamic relationship between Atienza and his academic role models, as well as his thoughts regarding contemporary debate topics within the area of philosophy of Law. Throughout the interview, Atienza is willing to reject the traditional paradigms of legal positivism in order to put forward new theories that should guide modern legal practices. In that sense, although he supports the importance of argumentation within the Law, Atienza remarks the importance of the application of a minimum of moral objectivism in our arguments. Finally, Atienza comments on the evolution of Latin American schools and the relevance that he predicts they will have in the future.
\end{abstract}

Keywords: Philosophy of Law - Natural law - Legal positivism - Post-positivism - Neoconstitutionalism

$\left.{ }^{*}\right) \quad$ Nota del Editor: la entrevista fue recibida el 29 de enero y su publicación fue aprobada el 6 de abril de 2019.

$\left({ }^{* *}\right) \quad$ La presente entrevista fue realizada por Francisco M. Mora-Sifuentes. Profesor-Investigador a Tiempo Completo. Departamento de Derecho-DDPG. Universidad de Guanajuato. Miembro del Sistema Nacional de Investigadores (Nivel-1) del Conacyt. Becario del Centro de Estudios Parlamentarios del H. Congreso del Estado de Guanajuato. Contacto: fm.mora@ugto.mx. 
Manuel Atienza Rodríguez (Oviedo, 1951) es uno de los filósofos del Derecho más influyentes en nuestra lengua. Catedrático de Filosofía del Derecho en la Universidad de Alicante, ha desarrollado una vasta obra en materia de argumentación jurídica contribuyendo así al llamado giro argumentativo en el Derecho. Lidera la Asociación lusfilosofía del Mundo Latino, surgida del proyecto i-Latina. Es Director de la Revista Doxa y fue Vicepresidente de la Asociación Mundial de Filosofía Jurídica y Social (IVR). Además de sus contribuciones en materia de argumentación que quedaron plasmadas en su Curso de Argumentación Jurídica (Trotta, 2018), entre su obra destacamos Filosofía del Derecho y transformación social, (Trotta, 2017); Las piezas del Derecho. Teoría de los enunciados jurídicos con J. Ruiz Manero. (Ariel, 1996). Habiendo realizado una amplia labor docente y de investigación, el Profesor Atienza ha sido investido Doctor Honoris Causa por la Universidad de Valparaíso, Chile; la Universidad de Buenos Aires, Argentina; la Universidad de la República, Uruguay; o la Pontificia Universidad Católica del Perú, entre otras. Francisco M. Mora Sifuentes, profesor del Departamento de Derecho de la Universidad de Guanajuato, tuvo la oportunidad de mantener la presente entrevista con él, misma que forma parte de una serie de conversaciones con filósofos del Derecho contemporáneo.

Francisco M. Mora-Sifuentes: Antes que nada, le agradezco profundamente que haya aceptado participar en este proyecto de entrevistas cuyo formato, como es evidente, retoma el que usted mismo utiliza en Doxa. Comencemos por algunas notas biográficas. Para ello podríamos ubicarnos en la etapa previa, así como en sus estudios de Derecho. ¿Cómo fue su etapa de bachillerato?, ¿hubo entonces algún hecho determinante que le despertase su vocación jurídica o por qué decidió estudiar la carrera de Derecho?, ¿cómo era la formación jurídica durante su etapa de estudiante en Oviedo? ¿A quiénes entre sus profesores de esos años de formación recuerda y por qué?

Manuel Atienza: Mi primera vocación fue, sin duda, la literatura. Mientras estudiaba el bachillerato leía mucho y mis intereses, para decirlo de manera un poco pedante, estaban entre la literatura y la filosofía. Creo que por eso me produjo tanta fascinación encontrarme con los diálogos de Platón (un prodigio desde el punto de vista literario y filosófico); la misma fascinación que sigo sintiendo hoy: a Platón se le puede leer desde muy joven, aunque, naturalmente, lo que uno extraiga de sus textos no sea lo mismo a una edad que a otra. En principio, yo quería estudiar periodismo, pero eso no era posible entonces en Oviedo y opté por Derecho (entré en la Universidad en el año 68). Luego, hice, también, periodismo (en los veranos) y he mantenido de alguna manera mi interés por escribir en los periódicos. De hecho, he publicado dos libros que tienen su origen en colaboraciones periodísticas: La guerra de las falacias y (con Fernando Bañuls), un libro que acaba de salir y que se titula Ética en imágenes. Yo creo que cuando uno tiene que decidir qué estudiar en la universidad es, por lo general, demasiado joven como para tomar una decisión bien fundada. Sobre todo, si pensamos en una disciplina como el Derecho que, en mi opinión, exige mucha experiencia (una cierta edad) para poder entender su sentido; quizás sea distinto en relación con las Matemáticas o la Física. Esa era, por cierto, la opinión de Aristóteles. En fin, yo creo que opté por estudiar Derecho porque intuía, de alguna forma, que era algo ligado a la filosofía, en su dimensión más práctica. $Y$ ahora estoy muy convencido de que así es: de alguna manera, el Derecho es una rama de la filosofía práctica.

Francisco M. Mora-Sifuentes: Su carrera se gestó durante la renovación de la filosofía del Derecho española de los años setenta y principios de los ochenta del siglo pasado encabezada por Elías Díaz y otros filósofos como Gregorio Peces-Barba. Si no me equivoco, esos fueron años muy importantes para la filosofía del Derecho en España, (en la presentación del primer número de Doxa se habla, incluso, de una nueva filosofía del Derecho). ¿Qué recuerdos guarda de esa época?, ¿qué problemas tuvo durante el franquismo y en qué medida ello influyó en su obra?

Si me permite un comentario, me resulta interesante indagar en qué medida estuvo condicionada la adscripción al positivismo jurídico de varios iusfilósofos de su generación por razones históricas, más que teóricas. Es decir, ser positivista, sin entrar en mayor detalle, por el momento, en España durante alguna época representaba un avance por razones asociadas a las libertades y a la democracia. Sin embargo, hoy en día, autores afines en un primer momento, usted mismo; si no me equivoco, han cambiado de parecer. ¿En qué medida el cambio de régimen permitió otra valoración de concepciones no-positivistas en España?

Manuel Atienza: La filosofía del Derecho en España ha vivido durante estas últimas décadas un periodo de cierto esplendor. $Y$ ese esplendor empieza, efectivamente con algunos autores como Elías Díaz o Juan-Ramón Capella que se opusieron, ya en los años 60, a la iusfilosofía oficial (un iusnaturalismo conservador y de escaso o 
nulo interés en el plano intelectual). Ellos dos, en mi opinión, han sido los grandes renovadores de la filosofía del Derecho en España. Yo soy discípulo de Elías Díaz, hice con él mi tesis de doctorado y luego he mantenido siempre un estrecho contacto con él; pero también he sido influido por Capella. Curiosamente, ambos han mostrado en cierto modo más interés por la filosofía política que por la filosofía estrictamente jurídica en lo que, creo, se asemejan a Bobbio. Yo soy, sin embargo, creo que podría decirlo así, más filósofo del Derecho, si bien, por supuesto, nunca he tenido dudas de que las dos disciplinas no pueden separarse más que de una forma muy relativa: se necesitan recíprocamente.

El fin del franquismo en España (la transición suele entenderse que va de 1975 (muerte de Franco) a 1981 (fracaso del golpe de Estado de aquel año), pasando por la aprobación de la Constitución en 1978) supuso un gran cambio en todos los sentidos, y también en los estudios iusfilosóficos. Durante el franquismo, la adscripción al positivismo jurídico (y la consiguiente crítica del Derecho natural) era una señal de oposición política al régimen y de modernidad intelectual. Y las grandes referencias teóricas eran efectivamente autores inequívocamente iuspositivistas: Kelsen, Hart. Ross o Bobbio; y de tendencia política progresista. Todos ellos estaban vinculados, de una u otra forma, al socialismo democrático. De todas formas, en España, en mis años de formación, la filosofía analítica (que representan esos autores) se introdujo al mismo tiempo que el marxismo y no necesariamente como concepciones contrapuestas, irreconciliables. Por ejemplo, Capella, que es el principal representante de la filosofía del Derecho de inspiración marxista, fue, también, el autor que introdujo la analítica (con un libro que tituló El Derecho como lenguaje). Creo que se debe a esa circunstancia el que yo no me haya considerado nunca un iuspositivista en sentido estricto. O sea, admiraba y seguía la obra de los autores mencionados, pero también he tenido siempre presente la otra tradición, la que tiene a Marx como su hito fundamental. Hoy sigo pensando que necesitamos apoyarnos en esas dos tradiciones (y rescatar también algo de la iusnaturalista, hay versiones del Derecho natural que nada o muy poco tienen que ver con lo que durante el franquismo era la filosofía, la ideología, jurídica oficial) para construir un tipo de filosofía del Derecho que no puede ser ya iuspositivista, sino más bien postpositivista. El positivismo jurídico, más que una concepción falsa del Derecho, es una concepción demasiado pobre y con la que no se puede dar cuenta de nuestros ordenamientos y operar dentro de los mismos.

Francisco M. Mora-Sifuentes: Ya hablando de su formación propiamente como filósofo del Derecho, y aquí utilizo la expresión en un sentido amplio, como su producción académica indica, me gustaría que dedicase un momento a responder con cierta profundidad a lo siguiente: ¿a quiénes estima sus profesores y por qué? En segundo lugar, ¿qué filósofos, jurídicos o no, han influido más en su pensamiento? ¿Qué significo para usted su estancia en Argentina con motivo de la redacción de su tesis doctoral?

Manuel Atienza: Ya he mencionado antes a dos: Elías Díaz y Juan Ramón Capella. Debo añadir también, entre los españoles, a Felipe González Vicén, con el que no tuve prácticamente contacto personal (él era catedrático en una de las Islas Canarias), pero cuya obra iusfilosófica me influyó mucho; y también a Javier Muguerza, el mayor filósofo de la moral español de las últimas décadas y a Gustavo Bueno. Y luego vienen los argentinos. Yo visité por primera vez Argentina en 1975, para completar el trabajo que estaba haciendo entonces sobre la filosofía del Derecho en ese país, y que fue mi tesis de doctorado, que leí en la Universidad de Oviedo en 1976. Aquella visita fue fundamental, porque me dí cuenta del extraordinario nivel que tenían entonces los estudios iusfilosóficos en aquel país, y creo que contribuí bastante a que los autores argentinos fueran conocidos en España. Por lo que se refiere a mi formación iusfilosóficas (y no sólo) yo soy por lo menos medio argentino. Con quienes he tenido más afinidad es con Ernesto Garzón Valdés (es con el que tengo la mayor deuda intelectual y personal) y con Carlos Nino. Pero debo también mucho a otros iusfilósofos argentinos como Genaro Carrió, Eugenio Bulygin, Carlos Alchourrón, Roberto Vernengo o Pachi Guibourg. Además de estos nombres quisiera añadir el de Renato Treves, el fundador de la sociología del Derecho en Italia, y el de Bob Summers, con el que pasé un inolvidable año sabático en Ithaca. Viendo ahora todo ese conjunto de autores, me parece que tengo que considerarme como muy afortunado.

Francisco M. Mora-Sifuentes: Pasemos a otras cuestiones. Un tema en el que ha insistido es en la necesidad de que los juristas dejen atrás el positivismo jurídico. Son varias las preguntas que quiero preguntarle al respecto. Me gustaría señalara las tesis que, a su juicio, caracterizan al positivismo jurídico y, sobre todo, me gustaría en que abundara por qué considera que tales tesis desembocan en una teoría o concepción del Derecho deficiente. Particularmente, me gustaría que desarrollara un poco más en qué 
sentido se puede dejar atrás el positivismo suscribiendo a la vez las tesis definitorias del mismo, esto es, no cuestionando la tesis de las fuentes sociales o de la separación conceptual entre Derecho y moral.

Manuel Atienza: Dejemos atrás el positivismo jurídico es el título de un artículo que escribí con Juan Ruiz Manero hace ya bastantes años. La tesis que ahí defendíamos, y que luego he desarrollado en muchos otros trabajos, venía a ser la siguiente: el positivismo jurídico fue una concepción del Derecho funcional en una etapa del desarrollo jurídico que concluyó con el advenimiento de lo que suele llamarse constitucionalismo. No es, por eso, la manera de entender el Derecho que necesitamos para operar en el contexto de los ordenamientos jurídicos contemporáneos. Pero el positivismo jurídico ha dejado un legado teórico muy importante y que no se puede desconocer, prescindir sin más de él. Necesitamos, como antes decía, una nueva concepción del Derecho que vaya más allá del positivismo jurídico y a la que cabe denominar postpositivismo, porque asume algunas tesis del positivismo jurídico, no todas.

Yo creo que la primera de las dos tesis del positivismo jurídico, la de las fuentes sociales es una tesis correcta (aunque haya algunas cosas que aclarar en la misma), pero la segunda, la de la separación conceptual entre el Derecho y la moral resulta manifiestamente insostenible; o, para decirlo con más precisión: desde ciertas perspectivas puede, debe, separarse el Derecho de la moral, pero desde otras es imposible hacerlo (por ejemplo, si se trata de identificar lo que establece el Derecho sobre determinada cuestión o de interpretarlo). Para decirlo de manera breve y un tanto brutal: el positivismo jurídico hoy en día es, más que otra cosa, un obstáculo que debemos superar para construir una filosofía del Derecho que sirva para lo que debe servir: para entender el Derecho y para poder orientar las prácticas jurídicas.

Francisco M. Mora-Sifuentes: Vinculado con lo anterior, hay cierta disputa terminológica, y no sé si conceptual, sobre la mejor manera de caracterizar a aquellas propuestas teóricas que alejándose del positivismo jurídico tampoco se consideran, como pudiera pensarse en un primer momento, iusnaturalistas. La etiqueta que parece haber hecho mayor fortuna en nuestro entorno es la de neoconstitucionalismo. Juan Antonio García Amado, por su parte, prefiere utilizar iusmoralismo para encuadrar a todas aquellas posiciones antipositivistas. Si no me equivoco, usted se opone fuertemente a la etiqueta neoconstitucionalismo y prefiere la de post-positivismo. ¿Qué diferencias hay entre ellas? ¿Por qué habría que preferir la segunda sobre la primera? y, sobre todo, ¿qué entiende por post-positivismo?

Manuel Atienza: Lo de neoconstitucionalismo es una invención de la escuela genovesa que envuelve un manifiesto error conceptual. O sea, el concepto está mal construido, porque su connotación (las notas que definirían a un autor neoconstitucionalista) no se corresponde con su denotación (los supuestos autores neoconstitucionalistas no defienden esas tesis). Mi razón para evitar usar esa expresión es, simplemente, de claridad conceptual. Toda la discusión en torno al neoconstitucionalismo es enormemente confusa, porque no se sabe de lo que se está hablando con precisión. Y lo curioso, por cierto, es que los responsables de toda esa enorme confusión son los iusfilósofos que han hecho de la claridad su principal seña de identidad. Para salir un poco de todo este lío, yo he propuesto que se considere como neoconstitucionalistas tan sólo a los autores que usan esa expresión para referirse a sus concepciones del Derecho. Lo que tiene como consecuencia que ni Dworkin, ni Alexy, ni Nino, ni MacCormick ni Ferrajoli serían autores neoconstitucionalistas. ¿Pero quiénes quedan entonces?

Lo de iusmoralistas es un rótulo (una alternativa al anterior) que se debe, efectivamente, a García Amado. Incluiría a los autores que niegan la tesis de la separación entre el Derecho y la moral y, en ese sentido, abarcaría a los autores antes mencionados (con la excepción de Ferrajoli). Pero el problema es que esa tesis de la no separación puede entenderse a su vez de diversas maneras, y eso es lo que hace que la propuesta de García Amado resulte también equívoca. Por dos razones: porque los autores iusnaturalistas también serían iusmoralistas (en realidad, ese es, me parece el propósito que tiene su propuesta), pero eso lleva a aproximar (o identificar) concepciones del Derecho que realmente son muy diferentes; y porque, como antes decía, la tesis de la separación (conceptual) entre el Derecho y la moral no es una cuestión de todo o nada.

Lo que define al postpositivismo es considerar al Derecho como una realidad dual. O sea, el Derecho no es, simplemente, un conjunto de normas, sino, sobre todo, una actividad, una práctica con la que se trata de lograr ciertos fines y valores. El Derecho no es, por lo tanto (simplemente), un objeto, una cosa que está ahí fuera y que se trata de describir y de explicar. Su esencia es 
funcional, práctica, de manera que lo que ha de preocuparnos sobre todo es lo que puede lograrse con el Derecho. Para decirlo con la terminología de lhering (a quien considero como el precursor del postpositivismo), el Derecho es una idea de fin, y de ahí que él lo paragonase con el arte de la navegación.

Francisco M. Mora-Sifuentes: Otro punto en el que también ha insistido es en la propia caracterización de la teoría y filosofía del Derecho. En el plano metateórico ha planteado que la misma debe superar, por decirlo de alguna forma, los márgenes hartianos; es decir, debe dejar de ser general y descriptiva para, en su lugar, sostener teorías particulares, valorativas o normativas. A su juicio, ¿por qué debemos abandonar la empresa de construir teorías generales y descriptivas del Derecho? ¿No supone ello que el Derecho pierda o difumine nuevamente su autonomía como objeto de estudio frente a la moral o la política?

Manuel Atienza: No se trata exactamente de que debamos dejar de construir teorías generales y descriptivas del Derecho. Se trata, en mi opinión, de que una teoría del Derecho acorde con lo anterior (con la concepción del Derecho que he llamado postpositivista) está interesada fundamentalmente en construir teorías normativas, teorías que sirvan para tratar de promover los fines y valores que definen una actividad; el aspecto descriptivo es, por así decir, una condición o un medio, pero no el propósito último de la teoría, precisamente porque el Derecho es una realidad práctica. Por lo demás, yo no pienso que una teoría adecuada del Derecho no deba ser también descriptiva y general. Hay aspectos de esa teoría que sí lo son (el análisis lógico del Derecho), pero una buena teoría del Derecho no puede consistir solamente en eso, no puede tener exclusivamente propósitos descriptivos; y dado que los ordenamientos jurídicos que han existido a lo largo de la historia difieren considerablemente entre sí, si nos atenemos únicamente a sus rasgos más generales, entonces corremos el riesgo de no captar aquello que puede permitir que la teoría incida realmente en la práctica.

Francisco M. Mora-Sifuentes: Usted ha participado en muchos de los debates en materia de iusfilosófica más animados de los últimos tiempos (distinción principios/reglas, Estado de Derecho/Estado constitucional, positivismo/nopositivismo o post-positivismo, etc.) con autores como Robert Alexy, Luigi Ferrajoli, Juan Carlos Bayón, Josep Joan Moreso, Luis Prieto Sanchís, si no me equivoco. También ha sostenido sendos diálogos con Francisco Laporta o Juan Ruiz Manero. Por tal motivo me gustaría preguntado lo siguiente, entre esas discusiones, o diálogos, con sus pares ¿cuáles le han resultado más estimulantes e instructivas y por qué razones?

Manuel Atienza: Es cierto que siempre me ha interesado la discusión: con quienes tienen opiniones iusfilosóficas que difieren mucho de las mías, pero también con otros a los que considero básicamente afines. Quizás tenga que ver con lo que antes comentaba: que mi interés por la filosofía y por la filosofía del Derecho tiene su origen en los diálogos platónicos. Acabo de redactar ahora la presentación a un libro que se titulará Comentarios e incitaciones. Una defensa del postpositivismo jurídico (aparecerá ya en 2019) y en la que contrapongo mi concepción del Derecho (postpositivista) a la de una serie de autores, algunos muy alejados de mi forma de entender el Derecho y la filosofía del Derecho, y otros muy próximos. Lo que ahí señalo es que, en mi experiencia, pensar es una acción básicamente colectiva y que consiste tanto en pensar con otros (con los que uno comparte unos mismos presupuestos y objetivos) como también contra otros. Y la verdad es que no creo que deba prescindirse de ninguna de esas dos modalidades: el pensamiento es dual y cooperativo, en el sentido de que sirve (ha de servir) tanto para destruir como para construir. La discusión con los afines permite precisar tus propias ideas, reforzarlas con nuevos argumentos, nuevas perspectivas. Pero la confrontación con las teorías que están muy alejadas de las propias puede resultar incluso más fructífera, en cuanto es un antídoto contra la tendencia al autismo (y al sectarismo) que, me parece, cada vez caracteriza más a nuestra cultura. Como ejemplo de esto último (de la discusión con los adversarios teóricos) puedo poner un librito que publiqué con Juan Antonio García Amado a propósito de la ponderación. Él es un crítico de la ponderación y yo considero que es un procedimiento argumentativo necesario en algunos casos. Cuando empezamos la discusión, los dos sabíamos que nuestras opiniones al respecto eran realmente opuestas y no pensábamos que ninguno fuera a cambiar sustancialmente de opinión, como efectivamente ocurrió. A pesar de lo cual, creo que los dos acabamos muy satisfechos con ese ejercicio de discusión libre y abierta y que por momentos pudo parecer incluso agresiva.

Francisco M. Mora-Sifuentes: Gran parte del reconocimiento que tiene ganado en el gremio proviene de su dilatado trabajo en el campo de la argumentación jurídica, mismo que quedó plasmado en su Curso (Madrid-Trotta, 2018). Desde su punto de vista ¿cuáles son las ventajas del enfoque del Derecho como argumentación? ¿Cuáles 
son los límites de la argumentación en el Derecho? Mauro Barberis ha sostenido que su propuesta supone una visión imperialista (otra más, como se ha dicho también de la moral o de la economía sobre el Derecho) que tiende a desdibujar la dicotomía interpretación-argumentación en favor de la última por su innegable carga axiológica. ¿Qué opinión le merece dicha crítica? ¿Sigue habiendo lugar para la discrecionalidad, para la decisión, en el Estado constitucional?

Manuel Atienza: En los últimos tiempos es frecuente hablar de un giro argumentativo en la teoría del Derecho contemporánea, que es especialmente acusado en los países del mundo latino. Yo he tratado de contribuir a ese giro, porque me parece que es algo muy saludable, casi diría que una necesidad, en países cuya cultura jurídica ha tenido tradicionalmente una fuerte impronta formalista. El Curso representa el resultado de muchísimo trabajo anterior en ese campo, y en el mismo trato de ofrecer de manera sintética y sistemática lo que (me parece) puede verse como una relativamente nueva materia jurídica. Divido la teoría (y práctica) de la argumentación jurídica en dos partes (siguiendo el modelo de las dogmáticas jurídicas tradicionales). La parte general contiene el desarrollo del concepto de argumentación, y para ello distingo tres aproximaciones al razonamiento jurídico: formal, material y pragmática (retórica y dialéctica). En la parte especial trato, a partir de lo anterior (de ese concepto complejo de argumentación), de mostrar cómo puede utilizarse todo ese arsenal teórico para responder a las tres grandes cuestiones argumentativas que los juristas tienen que afrontar en su práctica: cómo entender y analizar una argumentación; cómo evaluarla; cómo argumentar.

La crítica de Barberis me parece desenfocada. Yo no creo que el Derecho sea simplemente argumentación; es, además de eso, muchísimas otras cosas. Lo que sostengo es que la visión argumentativa del Derecho es de gran interés para enfocar muchísimas cuestiones teóricas y es también de gran rendimiento para la práctica. Escribí un libro que titulé El Derecho como argumentación, pero con ese título no pretendía reflejar ninguna tesis ontológica, no quería dar a entender que el Derecho fuera argumentación, de manera que no creo que tenga sentido hablar de una visión imperialista. Y en relación con lo último, creo que es importante distinguir entre discrecionalidad y arbitrariedad. La discrecionalidad tiene necesariamente un papel en nuestros Derechos, pero la arbitrariedad, no; o sea, no debería tenerlo. Esa es quizás la principal función de un enfoque argumentativo del Derecho: la lucha contra la arbitrariedad, esto es, contra las decisiones (en el ámbito que sea) carentes de justificación.

Francisco M. Mora-Sifuentes: Un presupuesto indispensable de la argumentación como empresa racional es la posibilidad de evaluar los argumentos como buenos o malos desde algún punto de vista. Usted ha sostenido que, para tal fin, es necesario o debemos predicar cierto objetivismo moral mínimo. ¿Qué debemos entender por esto último? ¿En qué medida se aleja del realismo u objetivismo moral tradicional? $Y$ sobre todo, ¿cuáles son las ventajas que, estima, presenta su postura frente a las posiciones escépticas en materia moral o no cognoscitivistas?

Manuel Atienza: El objetivismo moral es, efectivamente, una condición necesaria para poder dar sentido a nuestras prácticas jurídicas. Así, hoy en día todas nuestras constituciones incluyen la obligación para los jueces ( $y$, en general, para los órganos públicos) de justificar sus decisiones. Ahora bien, dado que el razonamiento jurídico justificativo contiene necesariamente alguna premisa moral (muchas veces está simplemente implícita), esa operación no podría llevarse a cabo si no existieran criterios objetivos acerca de la corrección moral. Cuando hablo de objetivismo moral mínimo, lo que quiero decir es que esa posición no debe confundirse con el absolutismo moral: el objetivista moral es un falibilista, en el sentido de que en su argumentación erige una pretensión de corrección, pero está abierto a la discusión racional y, por ello, está dispuesto a modificar sus opiniones morales, si surgen argumentos en contra de las mismas y de suficiente peso. Por lo demás, me parece importante recalcar que, en contra de lo que suele pensarse, el escepticismo moral no promueve en absoluto la crítica en materia moral: si no hay criterios objetivos de corrección, entonces no hay forma tampoco de oponerse racionalmente a las opiniones que consideramos equivocadas.

Francisco M. Mora-Sifuentes: Su interés por la obra de Carlos Marx y su importancia para una visión crítica no sólo del Derecho ha sido una constante en su obra. Desde su punto de vista ¿qué sigue vigente del pensamiento de Marx y en qué aspectos los juristas debieran seguir cultivándole? A su juicio, ¿de qué otros pensadores podemos beneficiarnos los juristas a fin de construir una obra comprometida; es decir, que trascienda el auditorio académico y resuene también en el ámbito civil o ciudadano? Si no me equivoco, Rudolf von lhering, el segundo Ihering para ser más exactos, con su enfoque funcionalista, y su estilo entre literario con 
ciertos toques humorísticos, es uno de sus preferidos. ¿Qué nos puede comentar sobre estas cuestiones?

Manuel Atienza: Efectivamente, he estado siempre interesado en la obra de Marx. A comienzos de los años 80 escribí un libro titulado Marx y los derechos humanos, y luego he tenido siempre muy presentes algunas de sus ideas, aunque nunca me he considerado un marxista. Aquel libro lo terminaba diciendo que a Marx deberíamos darle el tratamiento de un clásico, y eso es lo que hoy sigo pensando. Los autores clásicos son, de alguna manera, aquellos que han elaborado ideas que, por lo que sea, consideramos de particular importancia y de las que no podemos prescindir: bien sea para asumirlas, o para criticarlas. En relación con Marx, hay unas cuantas que a mí me parece siguen siendo esenciales para entender el Derecho. En un librito que publiqué en México hace algunos años, ¿Por qué leer a Marx hoy?, destacaba la idea de praxis, de ideología, de crítica de la sociedad burguesa (que incluye la de alienación, explotación, clases sociales, desigualdad o conflicto), así como una visión amplia, totalizadora, de la realidad social; y me parecía que prestar atención a su obra podía ayudar a orientar la teoría del Derecho en un sentido más pragmatista, funcional, crítico, materialista, incardinado en una concepción global de la sociedad, abierto hacia las ciencias sociales y comprometido con un proyecto ético-político de emancipación humana. Dicho esto, es obvio que hay también unas cuantas ideas que pueden encontrarse en las obras de Marx y que constituyen errores, algunos de considerable gravedad. Uno de ellos es el de no haber sabido comprender el significado moral, y no sólo político, de los derechos humanos. Por lo demás, el haber suprimido a Marx de la lista de los autores clásicos va probablemente ligado a la ceguera de tantos intelectuales y políticos que parecen haberse olvidado de que la mayor parte de las cuestiones que hoy consideramos progresistas tienen su origen en la tradición socialista (una tradición de la que forma parte fundamental Marx aunque, naturalmente, el socialismo no se reduce al marxismo). Esto lo digo porque, sobre todo en Latinoamérica, existe una manifiesta tendencia (un buen ejemplo de distorsión ideológica de la realidad) a sustituir el término socialista por el de liberal igualitarista; o sea, es como si nuestros Estados constitucionales hubiesen sido simplemente un producto del liberalismo, como si no hubiese habido también un pensamiento, un movimiento, socialista al que, repito, debemos, entre otras cosas, los derechos sociales.

En cuanto a lhering, él es, efectivamente, el jurista que yo considero más importante de la época contemporánea. De alguna forma (y simplificando un tanto las cosas), creo que el pensamiento jurídico de los últimos tiempos podría dividirse en dos grandes ramas: una es la de influencia kelseniana (el Derecho visto como un sistema de normas), y la otra tendría su origen en Ihering (en el segundo Ihering: el Derecho es una idea de fin, una práctica) y es la que, como antes decía, termina en el postpositivismo.
Francisco M. Mora-Sifuentes: Parte de su producción académica más relevante la ha realizado en coautoría con Juan Ruíz Manero, también Catedrático de Filosofía del Derecho en Alicante. Hasta donde recuerdo, en nuestro entorno, sólo Carlos Alchourrón y Eugenio Bulygin colaboraron así durante tantos años. ¿Cuáles fueron las motivaciones que les llevaron a trabajar de esa forma?, ¿hubo alguna empresa específica o producto de investigación que perseguían? En este mismo orden de ideas, ¿cuál ha sido su método de trabajo conjunto?; es decir, ¿cómo preparan o preparaban sus escritos?, ¿están trabajando en alguna coautoría actualmente?

Si me permite un comentario, tengo la impresión de que comienzan a hacerse patentes también algunos puntos de desencuentro entre ustedes. Por ejemplo, el profesor Ruiz Manero ha cuestionado cómo concibe usted el carácter pragmático de su propuesta teórica. Al respecto, sería muy interesante conocer algunos puntos específicos en que usted y Ruiz Manero se distancian, ¿podría abundar en esto?

Manuel Atienza: He escrito varios libros y artículos conjuntamente con Juan Ruiz Manero. Dos que considero particularmente relevantes son Las piezas del Derecho e llícitos atípicos. Fueron el resultado de una discusión prácticamente día a día y también del hecho de que nuestras concepciones del Derecho y de la filosofía del Derecho eran sustancialmente idénticas. La diferencia a la que se refiere la pregunta, lo del pragmatismo, era más que nada una cuestión lingüística. Nuestro trabajo conjunto ha terminado hace ya años, pero ello se debe a una serie de circunstancias que tienen, me parece, poco que ver con la manera de entender el Derecho y la filosofía del Derecho. De todas formas, en el Epílogo del último libro que publicamos en común, Para una teoría postpositivista del Derecho, y que tiene la forma de una conversación, quizás puedan encontrarse algunas diferencias iusfilosóficas entre nosotros que, en mi opinión, son más bien de acento.

Francisco M. Mora-Sifuentes: Ya ha salido a relucir Argentina en su itinerario vital. ¿Qué podría decirnos de otros países 
latinoamericanos? ¿Cuáles son las condiciones que se precisan para poder hablar de una escuela de pensamiento?, ¿considera usted que existe algo así como una escuela alicantina en Latinoamérica? ¿Cuál es su relación con la filosofía del Derecho mexicana, brasileña o peruana, por ejemplo? En definitiva, ¿qué opinión le merece la filosofía del Derecho que se cultiva en la actualidad en nuestra región?

Manuel Atienza: Yo creo que el futuro de la filosofía del Derecho del mundo latino está mucho más en América que en Europa. Hasta ahora, y seguramente todavía durante algún tiempo, en países como Italia o España pueden encontrarse algunos centros iusfilosóficos de alto nivel y que ofrecen una buena oportunidad de formación para los estudiantes o profesores latinoamericanos. Pero las cosas están cambiando y por razones bien comprensible, que no hay por qué lamentar, a mí me parece que en seguida se va a producir una nivelación, y luego un despegue de la filosofía del Derecho que se hace en Latinoamérica. En Alicante hemos promovido el desarrollo de una filosofía del Derecho para el mundo latino (la i-Latina) que ha celebrado ya dos congresos, con considerable éxito (el tercero, en 2020, será en México), y que espero pueda jugar un papel en el inmediato futuro en la construcción de una comunidad iusfilosófica de nuestros países. Como decía, nosotros estamos ahora en mejores condiciones para impulsar el proyecto, pero me parece obvio que el liderazgo (como ahora se dice) va a pasar más pronto que tarde al continente americano. Y está bien que sea así.

Francisco M. Mora-Sifuentes: Relacionada con la anterior pregunta, usted también ha defendido la necesidad de crear o, mejor, consolidar una comunidad iusfilosófica para el mundo latino que incluye, además de los países iberoamericanos, a Portugal, Italia o Francia. En este punto, ¿qué importancia tiene para nuestra disciplina y cómo puede sustraerse de los peligros del parroquianismo? Por otra parte, ¿cuál debe ser la postura de los teóricos del Derecho de dicha comunidad frente a la prevalencia del trabajo cultivado por ejemplo en el mundo anglosajón?, ¿cree que la mejor producción académica en nuestra lengua ha gozado del reconocimiento que su calidad amerita? Finalmente, ¿cuál fue experiencia del Congreso de i-Latina y cuáles los resultados obtenidos del mismo? ¿Qué sigue en ese proyecto?

Manuel Atienza: Se trata, me parece, de saber aprovechar lo que ya existe. Entre los países latinos, de uno y otro lado del Océano, las afinidades de todo tipo son evidentes. Compartimos (aproximadamente) una misma cultura y eso es lo que hace que, por ejemplo un español, no se sienta del todo un extranjero en Italia, en México o incluso en Brasil. En el último congreso que hemos tenido en la i-Latina, en Rio de Janeiro, esto resultaba evidente. Incluso cuando se trata de cuestiones abstractas, no se discute igual (por ejemplo, a propósito del objetivismo moral o de los derechos sociales) con un alemán, un estadounidense o un británico, que con un italiano, un mexicano y un brasileño. Eso no quiere decir que la filosofía del Derecho deba construirse de manera provinciana, prescindiendo de otras tradiciones. Pero sí que en lugar de ocuparnos de autores anglos o alemanes, digamos, de segunda fila, prestemos más atención a iusfilósofos muy relevantes de la tradición latina y que están prácticamente olvidados. Por poner un ejemplo, Carlos Vaz Ferreira ha sido el precursor de los precursores de la teoría de la argumentación contemporánea. Pero, ¿quién conoce ni siquiera su nombre? También me parece un despropósito la propensión a analizar problemas (y utilizar ejemplos) procedentes de otros sistemas jurídicos, en lugar de centrarnos en los generados en nuestros países y en nuestros ordenamientos jurídicos. Leyendo mucho de lo que se escribe en filosofía del Derecho en el mundo latino, uno tiene la impresión de que esos escritos parecen estar dirigidos a los profesores universitarios de Estados Unidos, de Alemania o de Gran Bretaña que, por supuesto, nunca (puede haber alguna excepción: pero es rarísima) van a prestarles el menor interés. A mí me parece que somos víctimas de un gran engaño generado en buena medida por las llamadas agencias de la evaluación de la investigación. En realidad, no existe algo así como una comunidad mundial de filósofos del Derecho (o, para ser más exacto, lo que existe no es parangonable a la comunidad de los matemáticos, los físicos nucleares o los neurocientíficos) y, por eso, no tiene sentido escribir trabajos iusfilosóficos como si existiera. Sin embargo, sí que existe (o puede llegar a existir) una comunidad de iusfilósofos del mundo latino con suficientes cosas en común como para leerse recíprocamente, generar un tipo de literatura iusfilosófica que pueda tener una incidencia en la práctica jurídica de esos países, etc.

Francisco M. Mora-Sifuentes: Pasando a otro orden de cuestiones, y ya casi para concluir, podría darnos algunas impresiones sobre este ejercicio, es decir, ¿cuál es el valor de la entrevista en este ámbito de conocimiento?, ¿por qué se decidió incluir este género de modo regular en su revista? 
Desde aquél primer número de Doxa, 1984, recuérdese, hasta las 35 entrevistas publicadas a la fecha (si no me equivoco) en ella, ¿qué contribución han supuesto? Si pudiera elegir tres filósofos (del Derecho) fallecidos ¿a quiénes le hubiera gustado entrevistar y por qué?

Manuel Atienza: La entrevista a intelectuales, en este caso, a iusfilósofos, ayuda, me parece, a entender mejor las ideas que podemos encontrar en sus obras. Permite además tener una percepción más viva de los autores y de las obras, y darse cuenta de que las ideas no caen del cielo, sino que surgen como consecuencia de muchos factores de muy diverso tipo, algunos de ellos más bien azarosos. Si no suena demasiado pretencioso, yo diría que se puede aprender mucha filosofía del Derecho leyendo, por ejemplo, las entrevistas que hemos publicado en Doxa; esa sección podría servir como una buena introducción a la disciplina. $Y$, la verdad, no sabría elegir tres nombres de iusfilósofos (supongo que del pasado) para entrevistar; tengo la impresión de que no sabría muy bien qué preguntarles.

Francisco M. Mora-Sifuentes: Por último: ¿en qué está trabajando actualmente?, ¿qué consejos daría a los jóvenes quienes están comenzando su carrera en teoría y filosofía del Derecho?, ¿a qué temas, relevantes a su juicio, podrían dirigir su interés? y, en fin, ¿cuáles son los 5 libros que, estima, son imprescindibles para nuestra disciplina?

Manuel Atienza: Ya antes he dicho que va a salir pronto un libro que tiene como título Comentarios e incitaciones. Una defensa del postpositivismo. A ese va a seguir otro (supongo que se publicarán en el mismo año, en 2019) del que también puedo dar el título: Apología del Derecho y otros ensayos. Hablando en general, me parece que los filósofos del Derecho tenemos que hacer un esfuerzo para salir de nuestra burbuja (o de la burbuja en la que cada uno vive; ahora hay muchas: la de los analíticos, la de los críticos, etc.) y conectarnos más con las ciencias sociales, con la filosofía y con el resto de la cultura. Esa es una condición indispensable para que la filosofía del Derecho pueda jugar un papel en la transformación social. Para mí, esta tendría que ser la función esencial de cualquier filosofía del Derecho que merezca la pena cultivar.

No es fácil dar consejos en los tiempos que corren. Todo cambia tan rápidamente que seguramente el mejor consejo a dar sea este (o estos): no te dejes llevar por la instantaneidad; el trabajo iusfilosófico no es a cortísimo plazo; elije algún tema que sirva para tu formación; no busques una recompensa inmediata; y, sobre todo, trata de integrarte en un grupo de trabajo en donde puedas encontrar personas que puedan orientar tu trabajo y con las que puedas discutir de manera abierta y ordenada.

En cuanto a los libros indispensables para conocer lo básico de la disciplina, quizás sean más de cinco, aunque no tienen por qué sobrepasar algunas pocas decenas. Si nos circunscribimos al siglo XX, en la lista no podrían faltar obras de autores como Ihering, Holmes, Kelsen, Ross, Hart, Bobbio, Dworkin o Nino. 